\title{
OPEN Animal sales from Wuhan wet markets immediately prior to the COVID-19 pandemic
}

\author{
Xiao Xiao ${ }^{1,2}$, Chris Newman ${ }^{3,4}$, Christina D. Buesching ${ }^{4,5}$, David W. Macdonald ${ }^{3}$ \& \\ Zhao-Min Zhou ${ }^{1,6 \bowtie}$
}

Here we document 47,381 individuals from 38 species, including 31 protected species sold between May 2017 and November 2019 in Wuhan's markets. We note that no pangolins (or bats) were traded, supporting reformed opinion that pangolins were not likely the spillover host at the source of the current coronavirus (COVID-19) pandemic. While we caution against the misattribution of COVID-19's origins, the wild animals on sale in Wuhan suffered poor welfare and hygiene conditions and we detail a range of other zoonotic infections they can potentially vector. Nevertheless, in a precautionary response to COVID-19, China's Ministries temporarily banned all wildlife trade on 26th Jan 2020 until the COVID-19 pandemic concludes, and permanently banned eating and trading terrestrial wild (nonlivestock) animals for food on 24th Feb 2020. These interventions, intended to protect human health, redress previous trading and enforcement inconsistencies, and will have collateral benefits for global biodiversity conservation and animal welfare.

Alongside extensive research into the epidemiology, virology and medical treatment of SARS-CoV-2, known generally as COVID-19, it is also vital to better understand and mitigate any role that may have been played by the illegal wildlife trade (IWT) in China, in initiating this pandemic ${ }^{1}$. COVID-19 was first observed when cases of unexplained pneumonia were noted in the city of Wuhan, Hubei Province, in late $2019^{2}$. Like the SARS-CoV epidemic (another coronavirus, for which there is still no cure) that began in Guangdong Province in $2002^{3}$, this latest coronavirus most closely resembles types found in bats ${ }^{4}$. Initial media coverage suggesting that COVID19 may have spilled-over via pangolins has been refuted ${ }^{5,6}$; probably pangolins are simply a natural reservoir of SARS-CoV-2 $2^{7-9}$ along with palm civets (Paguma larvata) ${ }^{10}$.

The World Health Organization (WHO) sent an investigative team to Wuhan, from 14 January-10 February 2021, to try to retrospectively ascertain what wildlife was being sold in local wet markets in this region ${ }^{1}$. Their findings were inconclusive, with markets having been closed down completely at that point for 4 months; however, they did recommend that pangolins should be included in the search for possible natural hosts or intermediate hosts of the novel coronaviruses ${ }^{1}$.

Here we present a unique and original dataset recording wild animal sales across Wuhan City's animal markets between May 2017 and November 2019. We investigate which wildlife species (including both wild-caught and farmed non-domesticated species) were actually being sold for food and as pets, what quantities were involved, and to what extent vendors violated their trading permits. We also list zoonotic pathogens recorded in Chinese wild animal markets and/ or farms since 2009, along with broader notes on infections established for these species. We evaluate these data in the context of China's renewed commitment to enforce and build on pre-existing laws within a culture of traditional wildlife exploitation. Finally, we make pragmatic policy recommendations for better regulating the animal trade pervasive in China, integrating with ethics, education and enforcement.

\footnotetext{
${ }^{1}$ Key Laboratory of Southwest China Wildlife Resources Conservation (Ministry of Education), China West Normal University, Nanchong 637009, People's Republic of China. 'Lab Animal Research Center, Hubei University of Chinese Medicine, Wuhan, People's Republic of China. ${ }^{3}$ Wildlife Conservation Research Unit, Department of Zoology, The Recanati-Kaplan Centre, University of Oxford, Oxford, UK. ${ }^{4}$ Cook's Lake Farming, Forestry and Wildlife Inc. (Ecological Consultancy), Queens County, NS, Canada. ${ }^{5}$ Department of Biology, The University of British Columbia/ Okanagan, Kelowna, BC, Canada. ${ }^{6}$ Key Laboratory of Environmental Science and Biodiversity Conservation (Sichuan Province), China West Normal University, Nanchong, People's Republic of China. ${ }^{\boxplus}$ email: zhouzm81@gmail.com
} 
a)

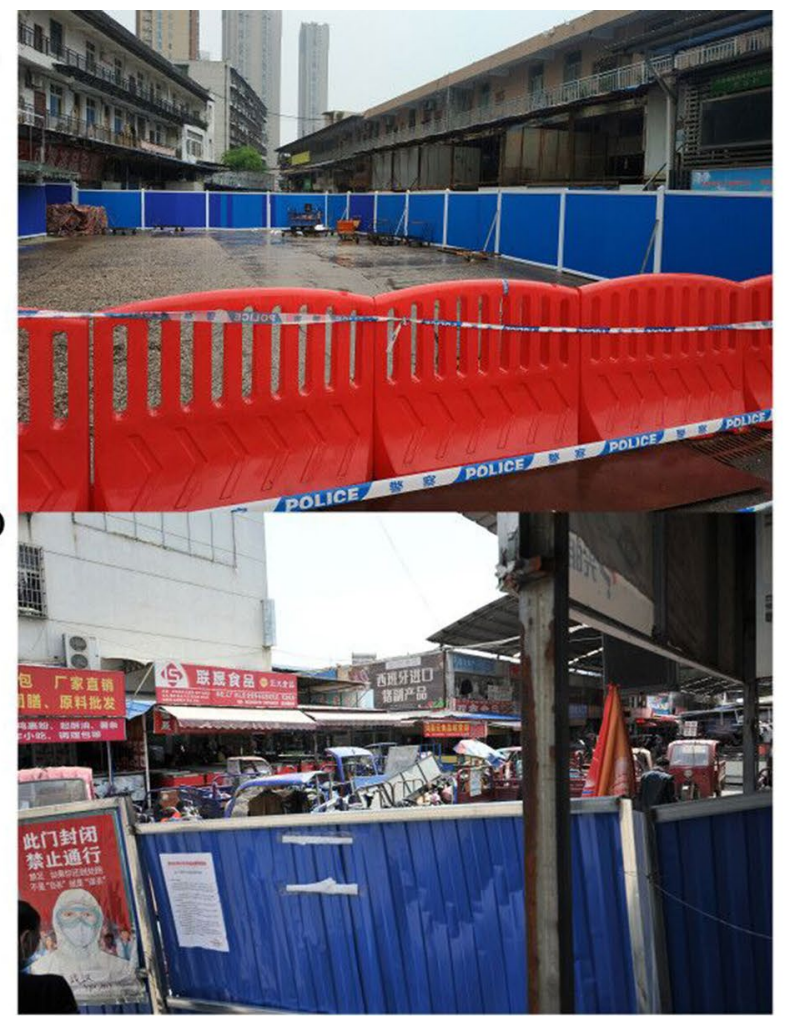

b)

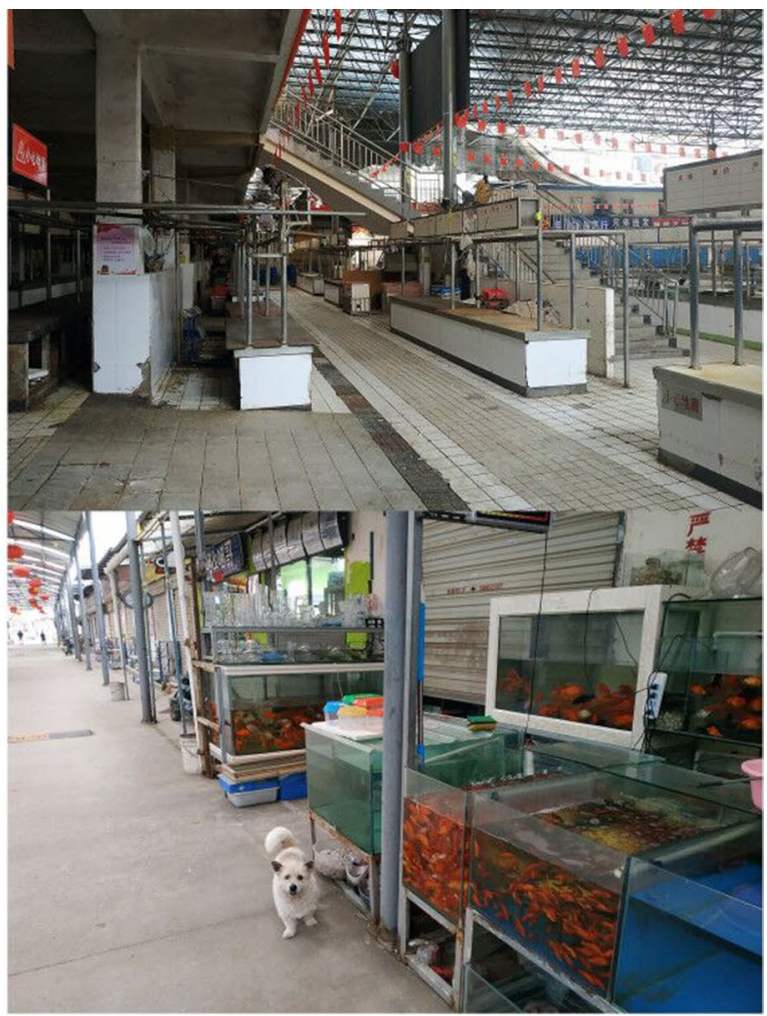

Figure 1. (a) Huanan Seafood market, (b) Qiyimen live animal market, (c) Baishazhou market and (d) Dijiao outdoor pet market (note stray dog) photographed on 10th April 2020.

\section{Materials and methods}

Serendipitously, prior to the COVID-19 outbreak, over the period May 2017-Nov 2019, we were conducting unrelated routine monthly surveys of all 17 wet market shops selling live wild animals for food and pets across Wuhan City (surveys were conducted by author X.X.). This was intended to identify the source of the tick-borne (no human-to-human transmission) Severe Fever with Thrombocytopenia Syndrome (SFTS), following an outbreak in Hubei Province in 2009-2010 in which there was an unusually high initial case fatality rate of $30 \%{ }^{11}$. These shops selling live, often wild, animals included two at Baishazhou market (a large market comprising c. 400 other types of shop), seven at Huanan seafood market (c. 120 other shops), four at Dijiao outdoor pet market (c. 100 other shops), and four at Qiyimen live animal market (c. 40 other shops). Other shops sold a variety of goods, such as live and butchered livestock and poultry, dairy produce, fish, shellfish, other food- related products and domesticated pets (Fig. 1 shows the appearance of these markets upon reopening on 8th April 2020).

As an objective observer unconnected to law enforcement X.X. was granted unique and complete access to trading practices. On each visit, vendors were asked what species they had sold over the preceding month and in what numbers, along with the prices (US\$1:RMB $¥ 6.759$ ) and origin of these goods (wild caught or captive bred/ farmed). Additionally, to substantiate interview data, the number of individuals available for sale at the time of each visit was noted, and animals were checked for gunshot wounds (from homemade firearms-gun ownership is strictly regulated in China ${ }^{12}$ ) or leg-hold (snap) trap injuries, indicative of wild capture. For 15 species ( 3 mammals and all 12 reptiles) sold by weight, vendors did not record the number of individuals sold. In these instances, we report numbers of individuals observed to be on sale during monthly visits.

In China, wild animals are state property protected by the Wild Animal Conservation Law (WACL 1988, revised in 2004, 2009, 2016 and 2018), in concert with the Criminal Law (Article 341) ${ }^{13}$. Any convicted trader of species, and/or products derived thereof, protected by China's list of Fauna under Special State Protection (LFSSP) and/or any non-native species listed in the Convention on International Trade in Endangered Species of Wild Fauna and Flora (CITES) Appendix I, II could face up to 15 years fix-term imprisonment accompanied by fines and/or the confiscation of property. Additionally, if any animal protected by China's List of Terrestrial Wild Animals of Significant Ecological, Scientific, or Social Value Protected by the State (LESS) is taken from a wild population and traded for the purpose of food, the offender could face up to 3 years fix-term imprisonment accompanied by criminal detention, surveillance and/or fines. Correspondingly, any utilization of these protected species should be approved by the wild animal conservation and animal quarantine administrations through various regulatory schemes. We therefore also noted if vendors had necessary permits allowing them to sell livestock; specifically a License for Domestication and Breeding of Wild Animals, a License for Trade and Processing of Wild Animals and the quarantine certificate, which must be displayed to customers according to the WACL (2018), Animal Epidemic Prevention Law (2013) and Special Provisions of the State Council on Strengthening the Food Safety Supervision and Administration (2007). 
All protocols in the market surveys were reviewed and approved by the Ethics Committee of Hubei University of Chinese Medicine (No. 20161111). All vendors provided informed written consent to participate in these surveys, and all protocols were performed in accordance with relevant guidelines and regulations.

\section{Results}

Animal sales from Wuhan's markets. Across all 17 shops, vendors reported total sales of 36,295 individuals, belonging to 38 terrestrial wild animal species, averaging 1170.81 individuals per month (Standard deviation $(\mathrm{SD})=445.01, \mathrm{n}=31$; Table 1 ). Including species sold by weight inflated this total to 47,381 individuals. Notably, no pangolin or bat species were among these animals for sale.

Almost all animals were sold alive, caged, stacked and in poor condition (Fig. 2). Most stores offered butchering services, done on site, with considerable implications for food hygiene and animal welfare. Approximately $30 \%$ of individuals from 6 mammal species inspected (labelled W in Table 1) had suffered wounds from gunshots or traps, implying illegal wild harvesting (Table 1). Thirteen of these 17 stores clearly posted the necessary permits from Wuhan Forestry Bureau allowing them to sell legitimate wild animal species (e.g., Siamese Crocodile (Crocodylus siamensis), Indian Peafowl (Pavo cristatus), Common Pheasant (Phasianus colchicus) and Amur hedgehog (Erinaceus amurensis)) for food; four shops had no such permit. Species names were given in Chinese only, with no clear taxonomic binomial designation. None of the 17 shops posted an origin certificate or quarantine certificate, so all wildlife trade was fundamentally illegal. Notably, vendors freely disclosed a variety of protected species on sale illegally in their shops, therefore they would not benefit from specifically concealing pangolin trade or the trade in any particular species, and so we are confident this list is complete (Table 1).

The most expensive wild mammal species sold for food was the marmot (Marmota himalayana) at over US\$ 25 per $\mathrm{kg}$, while raccoon dogs (Nyctereutes procyonoides) and badgers (Arctonyx albogularis and Meles leucurus) were priced at c. \$ 15-20 per kg; hedgehogs retailed for as little as \$ 2-3 each; all wild caught and intended as food. Squirrels (Callosciurus erythraeus and Sciurus vulgaris) were sold as pets for c. \$ 25 each. The most expensive wild bird sold for food was the Indian peafowl (Pavo cristatus) at \$ 56 each, while captive-bred crested myna birds (Acridotheres cristatellus), prized for imitating human speech, were sold as pets for c. \$300. The Sharp-nosed pit viper (Deinagkistrodon acutus) was the most expensive reptile, at $\$ 70$ per kg. For comparison, the average retail prices of pork, poultry and fish in Wuhan were $\$ 5.75, \$ 4.25$ and $\$ 2.32$, respectively (source: Municipal Bureau of Commerce http://sw.wuhan.gov.cn/html/ztzl/sjfb/scyx/jgjczb/).

These traded species are capable of hosting a wide range of infectious zoonotic diseases or disease-baring parasites (see Supplementary Table S1 for a non-exhaustive summary of studies reporting diseases in these species in China since 2009).

\section{Discussion}

Our findings illustrate both the range and extent of wildlife exploitation in Wuhan markets, prior to new trading bans linked to the COVID-19 outbreak, along with the poor conditions under which these animals were kept prior to sale. Circumstantially, the absence of pangolins (and bats, not typically eaten in Central China; media footage generally depicts Indonesia) from our comprehensive survey data corroborates that pangolins are unlikely implicated as spill-over hosts in the COVID-19 outbreak. This is unsurprising because live pangolin trading has largely ceased in China ${ }^{13}$.

We should therefore not be complacent, because the original source of COVID-19 does not seem to have been established. This is doubly important because false attribution can lead to extreme and irresponsible animal persecution. For instance, civets were killed en masse following the SARS-CoV outbreak ${ }^{5}$, and any unwarranted vilification or persecution of pangolins and bats in relation to COVID-19 would risk undermining otherwise very successful efforts to better protect and conserve wildlife in China.

Regarding our insights into broader IWT issues in Wuhan, the animals sold were relatively expensive, representing luxury food items, not cheap bushmeat (Table 1). We thus make an ethical distinction here between the subsistence consumption of bush meat in poorer nations, versus the sort of cachet attached to wild animal consumption in parts of the developed world, notably China ${ }^{14}$, but also Japan ${ }^{15}$. While c. $30 \%$ of mammals were clearly wild-caught, indicated by trapping and shooting wounds, the captive breeding of other species is commonplace in China. Raccoon dog fur farming is legal in China; however, due to a drop in fur prices, raccoon dogs are now frequently sold off in live animal markets, augmented by wild-caught individuals. Similarly, all American mink (Neovison vison) originated from fur farms-noting that SARS-CoV-2 has been reported in mink farms in Europe and North America ${ }^{16,17}$. In contrast, the captive breeding and sale of Siberian weasels (Mustela sibirica), is totally illegal in China, yet they are easy to breed, and sold openly, without attracting law enforcement. Indeed, prior to COVID-19 reforms, although enforcement officers from the Wuhan Forestry Bureau issued permits to market vendors, they were broadly disinterested in what species were sold. Furthermore, although animals were required to have an origin certificate and be quarantined to ensure they did not exhibit overt disease symptoms, no clear policy was enforced on these conditions. This is important because the species that were traded are capable of hosting a wide range of infectious zoonotic diseases or disease-baring parasites (Supplementary Table S1), aside from COVID-19. These range from potentially lethal viruses, for example, rabies, SFTS, H5N1, to common bacterial infections that, nevertheless, represent a risk to human health (e.g., Streptococcus). Indeed, globally, wildlife is thought to be the source of at least $70 \%$ of all emerging diseases ${ }^{18}$.

Legislative reform is also vital to clarify unequivocally which species are considered 'wild' and cannot be traded legally and safely. Another problem, as encountered by the WHO report is that, retrospectively, it proved difficult to ascertain which species were on sale, even to the genus level, relying solely on the responsible market authority's official sales records and disclosures ${ }^{1}$. As we $\mathrm{e}^{19,20}$, and others ${ }^{21}$, have proposed previously, China's LFSSP and LESS must be updated to apply proper binomials, and to align with recent taxonomic revisions; for instance, 


\begin{tabular}{|c|c|c|}
\hline Species on sale & $\begin{array}{l}\text { Monthly mean (and SD) number of individuals } \\
\text { sold }\end{array}$ & Price $($ mean $\pm \mathrm{SD}) \$$ per individual \\
\hline \multicolumn{3}{|l|}{ Mammals } \\
\hline Raccoon dog (Nyctereutes procyonoides) ${ }^{\mathrm{W}, \mathrm{R}, \mathrm{F}, \dagger}$ & $38.33 \pm 17.24(\mathrm{n}=30)$ & $63.32 \pm 15.46(\mathrm{n}=5)$ \\
\hline Amur hedgehog (Erinaceus amurensis) ${ }^{\mathrm{R}, \mathrm{F}, \uparrow}$ & $332.14 \pm 190.62(\mathrm{n}=28)$ & $2.66 \pm 0.41(\mathrm{n}=5)$ \\
\hline Siberian weasel (Mustela sibirica) ${ }^{\mathrm{W}, \mathrm{R}, \mathrm{F}, \dagger}$ & $(10.06 \pm 12.09, \mathrm{n}=31)$ & $11.24 \pm 3.07(\mathrm{n}=5)$ \\
\hline Hog badger (Arctonyx albogularis) ${ }^{\mathrm{W}, \mathrm{R}, \mathrm{F}, \dagger}$ & $(6.81 \pm 5.37, \mathrm{n}=31)$ & $72.79 \pm 34.08(n=5)$ \\
\hline Asian badger (Meles leucurus) $)^{\mathrm{W}, \mathrm{R}, \mathrm{F}, \dagger}$ & $12.24 \pm 7.39(\mathrm{n}=29)$ & $59.77 \pm 15.89(\mathrm{n}=5)$ \\
\hline Chinese hare (Lepus sinensis) ${ }^{\mathrm{W}, \mathrm{R}, \mathrm{F}, \dagger}$ & $168.96 \pm 89.06(\mathrm{n}=29)$ & $16.87 \pm 2.88(\mathrm{n}=5)$ \\
\hline Pallas's squirrel (Callosciurus erythraeus) ${ }^{\mathrm{R}, \mathrm{P}, \dagger}$ & $16.52 \pm 4.87(\mathrm{n}=23)$ & $25.74 \pm 7.59(\mathrm{n}=5)$ \\
\hline Masked palm civet (Paguma larvata) $)^{\mathrm{F} \dagger}$ & $10.69 \pm 8.42(\mathrm{n}=29)$ & $62.73 \pm 15.25(\mathrm{n}=5)$ \\
\hline Chinese bamboo rat (Rhizomys sinensis) ${ }^{\mathrm{F},}$ & $42.76 \pm 20.68(\mathrm{n}=29)$ & $18.64 \pm 7.58(\mathrm{n}=5)$ \\
\hline Malayan porcupine (Hystrix brachyura) ${ }^{\mathrm{F}, \dagger}$ & $10.00 \pm 0.00(\mathrm{n}=29)$ & $68.06 \pm 14.23(\mathrm{n}=5)$ \\
\hline Chinese muntjac (Muntiacus reevesi) ${ }^{\mathrm{F},}$ & $10.00 \pm 0.00(n=29)$ & $142.62 \pm 49.67(\mathrm{n}=5)$ \\
\hline Coypu $(\text { Myocastor coypus })^{\mathrm{F}}$ & $5.00 \pm 0.00(n=29)$ & $28.70 \pm 5.08(\mathrm{n}=5)$ \\
\hline Marmot $(\text { Marmota himalayana })^{\mathrm{F}}$ & $15.00 \pm 4.29(\mathrm{n}=20)$ & $81.37 \pm 11.70(\mathrm{n}=5)$ \\
\hline Red fox (Vulpes vulpes) $)^{\mathrm{F}, \dagger}$ & $30.00 \pm 0.00(n=25)$ & $60.96 \pm 21.68(n=5)$ \\
\hline Mink $(\text { Neovison vison) })^{\mathrm{F}}$ & $10.37 \pm 1.92(\mathrm{n}=27)$ & $34.62 \pm 14.78(\mathrm{n}=5)$ \\
\hline Red squirrel (Sciurus vulgaris) ${ }^{\mathrm{R}, \mathrm{P}, \dagger}$ & $16.43 \pm 9.51(\mathrm{n}=28)$ & $26.04 \pm 8.14(\mathrm{n}=5)$ \\
\hline Wild boar (Sus scrofa) ${ }^{\mathrm{W}, \mathrm{R}, \mathrm{F}, \boldsymbol{*}, \dagger}$ & $(4.17 \pm 5.77, \mathrm{n}=29)$ & $319.57 \pm 55.95(\mathrm{n}=5)$ \\
\hline $\begin{array}{l}\text { Complex-toothed Flying Squirrel (Trogopterus } \\
\text { xanthipes) }\end{array}$ & $5.17 \pm 27.85(\mathrm{n}=29)$ & $28.11 \pm 9.64(n=5)$ \\
\hline \multicolumn{3}{|l|}{ Birds } \\
\hline Collared crow (Corvus torquatus) ${ }^{\mathrm{R}, \mathrm{P}}$ & $9.14 \pm 20.18(n=29)$ & $54.74 \pm 8.43(\mathrm{n}=5)$ \\
\hline Spotted dove (Spilopelia chinensis) ${ }^{\mathrm{R}, \mathrm{F}, \dagger}$ & $200.00 \pm 0.00(\mathrm{n}=29)$ & $7.54 \pm 1.10(\mathrm{n}=5)$ \\
\hline Eurasian magpie (Pica pica) $)^{\mathrm{R}, \mathrm{F}, \mathrm{P}, \uparrow}$ & $21.54 \pm 28.53(n=13)$ & $10.21 \pm 3.56(\mathrm{n}=5)$ \\
\hline 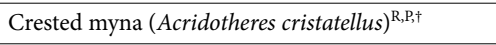 & $60.34 \pm 20.61(\mathrm{n}=29)$ & $15.39 \pm 16.23(\mathrm{n}=5)$ \\
\hline Chukar partridge (Alectoris chukar) ${ }^{\mathrm{F},}$ & $273.68 \pm 45.24(\mathrm{n}=19)$ & $6.66 \pm 1.38(\mathrm{n}=5)$ \\
\hline Ring-necked Pheasant (Phasianus colchicus) ${ }^{\mathrm{F} \dagger}$ & $80.00 \pm 0.00(n=26)$ & $14.80 \pm 5.44(\mathrm{n}=5)$ \\
\hline 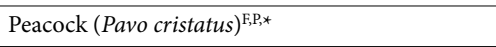 & $15.00 \pm 0.00(\mathrm{n}=15)$ & $55.63 \pm 20.33(\mathrm{n}=5)$ \\
\hline Guinea fowl (Numida meleagris) ${ }^{\mathrm{F}}$ & $35.00 \pm 15.81(\mathrm{n}=10)$ & $12.13 \pm 5.17(\mathrm{n}=5)$ \\
\hline \multicolumn{3}{|l|}{ Reptiles } \\
\hline Beauty rat snake (Orthriophis taeniurus) ${ }^{\mathrm{R}, \mathrm{E}, \dagger}$ & $(7.00 \pm 10.90, \mathrm{n}=28)$ & $22.78 \pm 15.36(\mathrm{n}=5)$ \\
\hline $\begin{array}{l}\text { Red large-toothed Snake (Dinodon } \\
\text { rufozonatum) })^{\mathrm{R}, \mathrm{F}, \mathrm{t}}\end{array}$ & $(7.78 \pm 11.56, \mathrm{n}=27)$ & $10.06 \pm 4.84(\mathrm{n}=5)$ \\
\hline Many-banded krait (Bungarus multicinctus) ${ }^{\mathrm{R}, \mathrm{F},}$ & $(3.18 \pm 3.32, \mathrm{n}=27)$ & $11.24 \pm 3.41(\mathrm{n}=5)$ \\
\hline Ringed water snake (Sinonatrix annularis) ${ }^{\mathrm{R}, \mathrm{P}, \dagger}$ & $(19.00 \pm 39.21, \mathrm{n}=29)$ & $3.25 \pm 1.24(\mathrm{n}=5)$ \\
\hline Short-tailed pit viper (Gloydius brevicaudus) ${ }^{\mathrm{R}, \mathrm{F}, \dagger}$ & $(5.96 \pm 10.30, n=27)$ & $7.84 \pm 1.93(\mathrm{n}=5)$ \\
\hline Chinese cobra (Naja atra) ${ }^{\mathrm{R}, \mathrm{F}, \dagger}$ & $(59.04 \pm 54.93, \mathrm{n}=28)$ & N/A \\
\hline Monocled cobra (Naja kaouthia) $)^{\mathrm{F},}$ & $(18.48 \pm 48.50, n=29)$ & $20.42 \pm 6.57(\mathrm{n}=5)$ \\
\hline Oriental rat snake (Ptyas mucosa $)^{\mathrm{F} \uparrow}$ & $(11.76 \pm 20.44, \mathrm{n}=29)$ & $18.94 \pm 3.21(\mathrm{n}=5)$ \\
\hline Sharp-nosed pit viper (Deinagkistrodon acutus) ${ }^{\mathrm{E}, t}$ & $(3.69 \pm 5.35, \mathrm{n}=26)$ & $41.13 \pm 16.65(\mathrm{n}=5)$ \\
\hline Siamese crocodile (Crocodylus siamensis) ${ }^{\mathrm{F} *}$ & $(2.07 \pm 2.53, \mathrm{n}=27)$ & N/A \\
\hline Big-eyed rat snake (Ptyas dhumnades) ${ }^{\mathrm{R}, \mathrm{F}, \uparrow}$ & $(121.10 \pm 138.11, \mathrm{n}=29)$ & $10.36 \pm 2.09(\mathrm{n}=5)$ \\
\hline King rat snake (Elaphe carinata) ${ }^{\mathrm{R}, \mathrm{F}, \dagger}$ & $(104.97 \pm 85.07, n=29)$ & N/A \\
\hline
\end{tabular}

Table 1. List of 38 species sold in Wuhan City markets between May 2017-Nov 2019, including the mean number of live individuals sold per month and price (mean $\pm S D ; n=$ survey rounds). Individuals sourced directly from the wild were inferred from wounds $(\mathrm{W})$ and/or according to vendor responses $(\mathrm{R})$. Species were sold either for food (F) and/or pets (P). The permitted species listed on the vendor's license are labelled with a * symbol. The 31 species labelled with $\dagger$ are protected under the LESS. Because all reptiles and 3 mammal species (Siberian weasel (Mustela sibirica), Hog badger (Arctonyx albogularis) and Wild boar (Sus scrofa)) were sold by weight, vendors did not record the number of traded individuals for these species. Therefore, we include in parenthesis the average number of individuals X.X. counted on sale on his monthly market visits. Similarly, because reptiles were priced by weight (Chinese cobra (Naja atra): $\$ 20.71 \pm 4.68(\mathrm{n}=5)$ per kg; Siamese crocodile (Crocodylus siamensis): $\$ 21.01 \pm 5.38(\mathrm{n}=5)$ per kg; King rat snake (Elaphe carinata): $\$ 21.90 \pm 5.77$ $(\mathrm{n}=5)$ per $\mathrm{kg}$ ), we cannot give a price per individual, and thus indicate this as N/A in the Table. Standard deviation per species reflects variation in sales per month; complete consistency $(S D=0)$ implies a regular supply of individuals. 

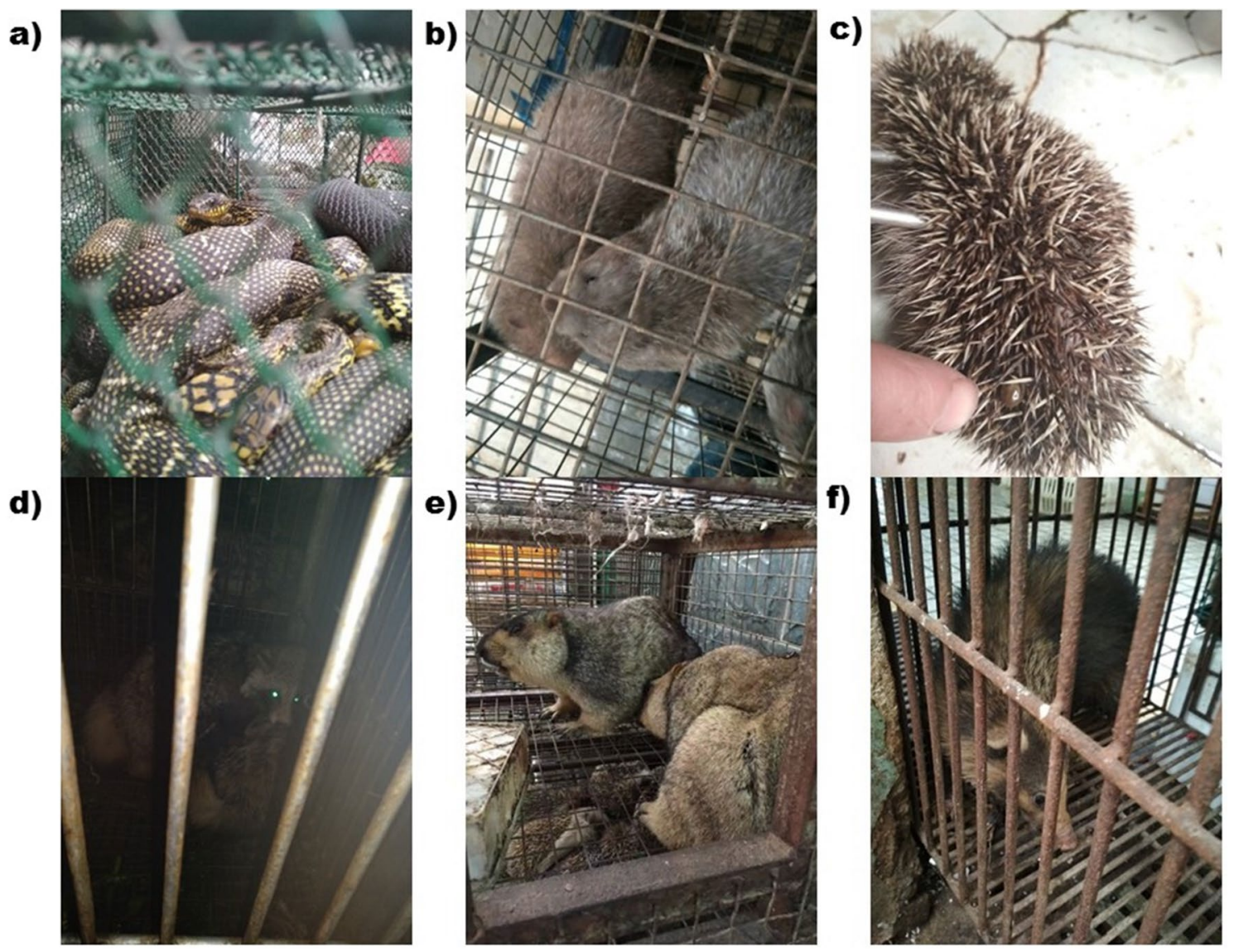

Figure 2. Poor welfare of animals on sale in Huanan seafood market: (a) King rat snake (Elaphe carinata), (b) Chinese bamboo rat (Rhizomys sinensis), (c) Amur hedgehog (Erinaceus amurensis) (the finger points to a tick), (d) Raccoon dog (Nyctereutes procyonoides), (e) Marmot (Marmota himalayana) (beneath the marmots is a cage containing hedgehogs), and (f) Hog badger (Arctonyx albogularis).

cobra snakes (Nada atra) can be farmed legally for food with permits, but wild caught species, such as water snakes and wolf snakes were also sold in Wuhan, labelled simply as 'snakes'. Such an application of clear species names would allow for more effective prosecutions ${ }^{19}$. Furthermore, the WHO reports that market authorities claimed all live and frozen animals sold in the Huanan market were acquired from farms officially licensed for breeding and quarantine, and as such no illegal wildlife trade was identified ${ }^{1}$. In reality, however, because China has no regulatory authority regulating animal trading conducted by small-scale vendors or individuals it is impossible to make this determination ${ }^{1,21}$. Similar discrepancies concerning species identification and origins afflict investigations around the world ${ }^{22}$.

Another important animal trade that requires attention, outside of exploitation as food, is the supply of pets, like the squirrels and crested myna birds sold in Wuhan's market. Our previous research found annual trade volumes equivalent to c. 17,000 parrots and c. 160,000 turtles (many turtles being invasive if escaping to the wild) sold online as pets via Taobao.com between 2016-2017, in contravention of China's WACL and/or the Animal Epidemic Prevention Law $^{23-25}$. While not currently the vector of any major viral epidemics, it would be naive to imagine that unconventional pets do not still also pose a serious concern for public health ${ }^{26}$. This potential for disease is likely exacerbated by poor sanitary and welfare conditions (Fig. 2).

\section{Conclusion}

Ultimately, changing the attitudes of consumers is crucial to reduce IWT in China. Efforts to stem the trade in charismatic species, such as elephants/ivory, rhino/horn, tiger bones, etc., have achieved modest success, and have garnered worldwide media attention and public concern ${ }^{27}$. Nevertheless, despite a general decrease in wildlife poaching and trafficking in China ${ }^{12}$, attempts to dissuade people from consuming lower-profile, but also highervolume, species have still fallen-short. Crucially, efforts must be made to change the normative values of consumers through education, raising awareness not only for health, but also for animal welfare and global biodiversity concerns, else continued demand, despite recent national bans, may merely push suppliers into black-market and dark-web operations ${ }^{23}$. Our own previous investigation found that, in China, a substantial desire to purchase and/or own wildlife products as 'prestige items' still transcends social classes, age groups, education levels and rural versus urban residents, even though this involves breaking the law ${ }^{14}$. In major part this is because protective legislation has not been enforced consistently, fostering a nonchalant disregard for wildlife exploitation ${ }^{23}$. 
President Xi Jinping has said that: the COVID-19 outbreak is a major test of China's system and capacity for governance, and we must sum up the experience and draw a lesson from it. In an early precautionary response to the COVID-19 crisis, on the 26th of January 2020, the Chinese government (State Administration for Market Regulation, Ministry of Agriculture and Rural Affairs and National Forestry and Grassland Administration) temporarily banned the sale of all wild animal and their products in markets, restaurants and over e-commerce, to least until the conclusion of the epidemic. Subsequently, on 24th Feb 2020, the Standing Committee of the National People's Congress implemented a permanent ban on trading terrestrial wild (non-livestock) animals and consuming them as food. The Hubei provincial government announced on 11th April 2020 that the sale of live wild animals and poultry will be strictly prohibited as markets re-open in Wuhan. Ultimately China plans to invest c. \$30 million to update Wuhan open-air markets to megamalls and inspire social capital. This is a major and commendable step, redressing previous tacit tolerance for many forms of wildlife trade in China, often already illegal under WACL and/or the CITES, which also carries a huge collateral benefit for global biodiversity and animal welfare 28 , 29. In response to the pandemic, on April 12th 2021 the WHO (co-signed by UNEP and OIE) released interim guidance for 'Reducing public health risks associated with the sale of live animals on mammalian species in traditional food markets ${ }^{30}$. Adopting these more responsible practices has the potential to save countless lives in the future.

\section{Data availability}

All datasets used in this study are included in the main text and the electronic supplementary material.

Received: 21 October 2020; Accepted: 27 May 2021

Published online: 07 June 2021

\section{References}

1. Joint WHO-China Study. WHO-convened global study of origins of SARS-CoV-2: China part. https://www.who.int/publicatio $\mathrm{ns} / \mathrm{i} /$ item/who-convened-global-study-of-origins-of-sars-cov-2-china-part (2021).

2. Huang, C. L. et al. Clinical features of patients infected with 2019 novel coronavirus in Wuhan, China. The Lancet 395(10223), 497-506 (2020).

3. Zhong, N. S. et al. Epidemiology and cause of severe acute respiratory syndrome (SARS) in Guangdong, People's Republic of China, in February, 2003. The Lancet 362(9393), 1353-1358 (2003).

4. Zhou, P. et al. A pneumonia outbreak associated with a new coronavirus of probable bat origin. Nature 579, 270-273 (2020).

5. Cyranoski, D. Mystery deepens over animal source of coronavirus. Nature 579, 18-19 (2020).

6. Boni, M. F. et al. Evolutionary origins of the SARS-CoV-2 sarbecovirus lineage responsible for the COVID-19 pandemic. Nat. Microbiol. 5(11), 1408-1417 (2020).

7. Zhang, T., Wu, Q. \& Zhang, Z. Probable pangolin origin of SARS-CoV-2 associated with the COVID-19 outbreak. Curr. Biol. 30, 1346-1351.e2 (2020).

8. Lam, T. T. Y. et al. Identifying SARS-CoV-2-related coronaviruses in Malayan pangolins. Nature 583, 282-285 (2020).

9. Xiao, K. et al. Isolation of SARS-CoV-2-related coronavirus from Malayan pangolins. Nature 583, 286-289 (2020).

10. Ge, X. Y. et al. Isolation and characterization of a bat SARS-like coronavirus that uses the ACE2 receptor. Nature 503, 535-538 (2013).

11. Yu, X. J. et al. Fever with thrombocytopenia associated with a novel bunyavirus in China. N. Engl. J. Med. 364(16), 1523-1532 (2011).

12. Shao, M. L., Newman, C., Buesching, C. D., Macdonald, D. W. \& Zhou, Z. M. Understanding wildlife crime in China: Sociodemographic profiling and motivation of offenders. PLoS ONE 16(1), e0246081 (2021).

13. Zhou, Z. M., Zhou, Y., Newman, C. \& Macdonald, D. W. Scaling up pangolin protection in China. Front. Ecol. Environ 12(2), 97-98 (2014).

14. Zhou, Z. M. et al. Private possession drives illegal wildlife trade in China. Front. Ecol Environ. 13(7), 353-354 (2015).

15. Kaneko, Y., Buesching, C. D. \& Newman, C. Japan: Unjustified killing of badgers in Kyushu. Nature 544(7649), 161 (2017).

16. Munnink, B. B. O. et al. Transmission of SARS-CoV-2 on mink farms between humans and mink and back to humans. Science 371(6525), 172-177 (2021).

17. Boklund, A. et al. SARS-CoV-2 in danish mink farms: course of the epidemic and a descriptive analysis of the outbreaks in 2020. Animals 11(1), 164 (2021).

18. Can, Ö. E., D'Cruze, N. \& Macdonald, D. W. Dealing in deadly pathogens: Taking stock of the legal trade in live wildlife and potential risks to human health. Glob. Ecol. Conserv. 17, e00515 (2019).

19. Zhou, Z. M. et al. Revised taxonomic binomials jeopardize protective wildlife legislation. Conserv. Lett. 9, 313-315 (2016).

20. Zhou, Z. M. et al. China: Outdated listing puts species at risk. Nature 525(7568), 187-187 (2016).

21. Xiao, L., Lu, Z., Li, X., Zhao, X. \& Li, B. V. Why do we need a wildlife consumption ban in China?. Curr. Biol. 31(4), R168-R172 (2021).

22. Dell, B. et al. Species misidentification in local markets: Discrepancies between reporting and molecular identification of bushmeat species in northern Uganda. One Health 13, 100251 (2021).

23. Ye, Y. C. et al. Effects of regional economics on the online sale of protected parrots and turtles in China. Conserv. Sci. Pract. 2, e161 (2020).

24. Liu, S. et al. E-commerce promotes trade in invasive turtles in China. Oryx 55, 1-4 (2020).

25. Yin, R. Y. et al. China’s online parrot trade: Generation length and body mass determine sales volume via price. Glob Ecol. Conserv. 23, e01047 (2020).

26. Back, D. S., Shin, G. W., Wendt, M. \& Heo, G. J. Prevalence of Salmonella spp. in pet turtles and their environment. Lab. Anim. Res. 32(3), 166-170 (2016)

27. Meng, X. Re: Report on the implementation mentation of Resolution Conf. 12.5 (Rev. CoP16). (CITES Management Authority PRC, 2013).

28. Montgomery, R. A. \& Macdonald, D. W. COVID-19, health, conservation, and shared wellbeing: details matter. Trends Ecol. Evol. 35, 748-750 (2020).

29. Zhou, Z. M., Buesching, C. D., Macdonald, D. W. \& Newman, C. Clamp down on trade-ban violations. Nature 578, 217 (2020).

30. World Health Organization, the World Organisation for Animal Health, \& UN Environment Programme. Reducing public health risks associated with the sale of live wild animals of mammalian species in traditional food markets. https://www.who.int/publi cations/i/item/WHO-2019-nCoV-Food-safety-traditional-markets-2021.1 (2021). 


\section{Acknowledgements}

C.N. was supported by the H.N. Southern memorial Fellowship. Z.M.Z. was supported by the scientific research foundation of China West Normal University (16E013, 17BO10).

\section{Author contributions}

X.X. collected these data; C.N., C.D.B. and Z.M.Z. contributed to the concept and writing of the manuscript; D.W.M. participated in scientific discussions; Z.M.Z. supervised and managed the project.

\section{Competing interests}

The authors declare no competing interests.

\section{Additional information}

Supplementary Information The online version contains supplementary material available at https://doi.org/ 10.1038/s41598-021-91470-2.

Correspondence and requests for materials should be addressed to Z.-M.Z.

Reprints and permissions information is available at www.nature.com/reprints.

Publisher's note Springer Nature remains neutral with regard to jurisdictional claims in published maps and institutional affiliations.

(c) (i) Open Access This article is licensed under a Creative Commons Attribution 4.0 International License, which permits use, sharing, adaptation, distribution and reproduction in any medium or format, as long as you give appropriate credit to the original author(s) and the source, provide a link to the Creative Commons licence, and indicate if changes were made. The images or other third party material in this article are included in the article's Creative Commons licence, unless indicated otherwise in a credit line to the material. If material is not included in the article's Creative Commons licence and your intended use is not permitted by statutory regulation or exceeds the permitted use, you will need to obtain permission directly from the copyright holder. To view a copy of this licence, visit http://creativecommons.org/licenses/by/4.0/.

(C) The Author(s) 2021 